Research Article

\title{
Willingness to Pay for Social Health Insurance and Its Predictors among Government Employees in Mujja Town, Ethiopia
}

\author{
Feleku Mekonnen Degie ${ }^{D},{ }^{1}$ Yeshambel Agumas Ambelie, ${ }^{2}$ Yared Mulu Gelaw, \\ Getahun Fentaw Mulaw $\left(\mathbb{D},{ }^{3} \text { and Fentaw Wassie Feleke }{ }^{3}\right)^{3}$ \\ ${ }^{1}$ North Wollo Zonal Health Department, Woldia, Amhara Regional State, Ethiopia \\ ${ }^{2}$ School of Public Health, College of Medicine and Health Sciences, Bahirdar University, Bahir Dar, Ethiopia \\ ${ }^{3}$ School of Public Health, College of Health Science, Woldia University, Woldia, Ethiopia \\ Correspondence should be addressed to Feleku Mekonnen Degie; felekumekonen26@gmail.com
}

Received 13 June 2020; Revised 10 September 2020; Accepted 24 February 2021; Published 4 March 2021

Academic Editor: Sylvia H. Hsu

Copyright (C) 2021 Feleku Mekonnen Degie et al. This is an open access article distributed under the Creative Commons Attribution License, which permits unrestricted use, distribution, and reproduction in any medium, provided the original work is properly cited.

\begin{abstract}
Background. Social health insurance is one of the possible organizational mechanisms for raising and pooling funds to finance health services, private health insurance, community insurance, and others. Objective. The study was aimed to assess willingness to pay for social health insurance and associated factors among government employees in Mujja town, Ethiopia. Methods. An institutional-based cross-sectional study was conducted on the total sample size of 375 study respondents. A simple random sampling technique was employed. Data were entered into EPI info 7 and analyzed by Statistical Package for Social Sciences version 22.0. Multivariable logistic regression was used to identify independent predictors by controlling confounding variables. Statistical significance was declared at $p<0.05$. Results. This study revealed that $37.6 \%$ (95\% CI: $33.1 \%$, $42.61 \%)$ respondents were willing to pay for social health insurance. In the final model, respondents who ever heard about health insurance schemes were seven times $(A O R=7.205 ; 95 \%$ CI: $1.385,37.475)$ more likely willing to pay for social health insurance. Thos who had history of difficulty and having other source to cover medical bills were $92.6 \%$ (AOR $=0.074 ; 95 \% \mathrm{CI}$ : $0.009,0.612)$ and $94.6 \%(A O R=0.054 ; 95 \% \mathrm{CI}: 0.011,0.257)$ less likely to pay, respectively. Conclusions. Willingness to pay for social health insurance was low. Being heard about health insurance, history of difficulty, and having other sources to cover medical bills were associated factors. Thus, it is recommended that media promotion and these factors should be considered for the successful implementation of the scheme.
\end{abstract}

\section{Background}

Social health insurance (SHI) is one of the possible organizational mechanisms for raising and pooling funds to finance health services, along with tax-financing, private health insurance, community insurance, and others [1]. Health insurance is promoted in developing countries since the 1990s to improve access to healthcare services [2]. SHI schemes are provided by governments and nongovernment organizations to its citizens, especially to low- and middleincome populations [3].
Significant proportions of people all over the world suffer and die due to a lack of access to basic healthcare services. In low- and middle-income countries alone, 150 million people suffer a health-related financial catastrophe each year, and 100 million people are pushed into poverty as a result of outof-pocket (OOP) health expenditure [4-7].

Introducing SHI was considered as one of the most powerful risk pooling mechanisms in most developing countries to achieve universal health coverage (UHC). The UHC had been achieved in many countries in the world by establishing SHI as the country's healthcare financing 
mechanism [8]. It improves access to health services by removing catastrophic health expenditures by pooling funds to allow cross-subsidization between the rich and poor and between the healthy and the sick [9].

The Ethiopian government developed a health insurance strategy in 2008, and two types of health insurance have been proposed since 2010, Community Based Health Insurance (CBHI) and SHI $[10,11]$. The SHI was intended to cover the employed and their family members, approximately $11 \%$ of the population (public servants, permanent employees working in private organizations, and pensioners). Enrollment in SHI is compulsory and the proposed contribution is $3 \%$ of their salary [10]. But it is impossible to force people to join SHI because it will lead to problems of low coverage, adverse selection, and fragmented risk pools [4].

The Ethiopian healthcare system is characterized by high OOP expenditure, increased healthcare needs, inability to mobilize more resources for health, and inability to fully recover costs of care incurred by beneficiaries [12]. The Ethiopian health insurance coverage of the total population is very low, representing only $7.5 \%$ [13].

Despite the government plan to fully implement SHI by 2014 [14-17], it has been repeatedly postponed, which is largely due to strong resistance from government employees. There was limited evidence on willingness to pay and associated factors for the SHI scheme in Ethiopia, the Amhara region particularly in the study area, Muja. Hence, this study was conducted to explore the willingness to pay for SHI and associated factors among government employees in Mujja town, northeast Ethiopia. The study focused on teachers, health professionals, polices, and women and child affairs employed in Mujja town.

\section{Methods and Materials}

2.1. Study Design, Period, and Setting. A quantitative institutional-based cross-sectional study design was carried out from February 15 to May 20/2016. Mujja town is one of the 15 North Wollo administrative woredas, which is located around $594 \mathrm{Km}$ from Addis Ababa and $345 \mathrm{~km}$ from Bahir Dar. This is bounded by Tigray in the North, Meket, and Gubalafto woreda in the South, Kobo woreda in the East, and Lasta woreda in the West. There were around 981 employees working in a governmental institution in the town, out of which 651 and 330 were male and female population, respectively. With regard to health infrastructure; there was only one functional health center.

2.2. Source, Study Population, and Study Unit. The source population included individuals who were working in all government institutions in Mujja town while the study population was employees who were working in the randomly selected government institutions. The study units were employees on whom the data were actually collected.

2.3. Eligibility Criteria. Full-time employees working for more than six months in government institutions were included. Those employees who were working under CBHI unit were excluded.

2.4. Sample Size and Sampling Technique. The sample size was determined by using a single population proportion formula with the following assumptions: the proportion of willingness to pay for SHI as $74.4 \%$ [18], margin of error $0.05 \%$, design effect $2,95 \%$ confidence level, and $10 \%$ nonresponse rate.

$$
n=\operatorname{diff} \frac{\left(Z^{2} P(1-P)\right)}{d^{2}}=2 \frac{(1.96)^{2}(0.744)(0.256)}{(0.05)^{2}}=586
$$

After adding $10 \%$ of nonresponse rate, the final sample size will be 645 .

Since the source populations were less than 10,000, adjustments were also done.

$$
\text { Adjusted } n=\frac{n}{1+(n / N)}=\frac{645}{1+(645 / 981)}=390
$$

Therefore, the final sample size after adjustment is 390 .

2.5. Sampling Procedure. Simple random sampling technique was used. The governmental institutions included were the health sector, education sector, police, and women and child affairs. Then, the sample size was allocated proportionally for each sector, and finally, study units were selected by simple random sampling (Figure 1).

2.6. Data Collection Tools and Quality Assurance. Data were collected by a self-administered semistructured questionnaire on selected governmental employees. The questionnaire, developed through a critical review of relevant literature $[14,15,17,19-21]$, was composed of three parts. These were socio-demographic and economic characteristics, health status, and healthcare utilization of the individuals, exposure, and perception regarding insurance. Four degree-holder statisticians as data collectors and two BSc male public health professionals as supervisors working in the district were recruited.

The research questionnaire was prepared in the English version and translated into the local language (Amharic) and retranslated back to English to check consistency by different peoples. Before the actual data collection, the questionnaire was pretested on $10 \%$ of the calculated sample size in none selected governmental institutions of Muja town, and then necessary modification was done accordingly before the actual data collection.

Data collectors and supervisors who were fluent in the local language were recruited and two days of training was given before the actual data collection. The training was on interviewing skills, probing techniques of the SHI scheme. Continuous supervision and follow up of the data collectors were done. The collected data were handled and stored carefully and appropriately. 


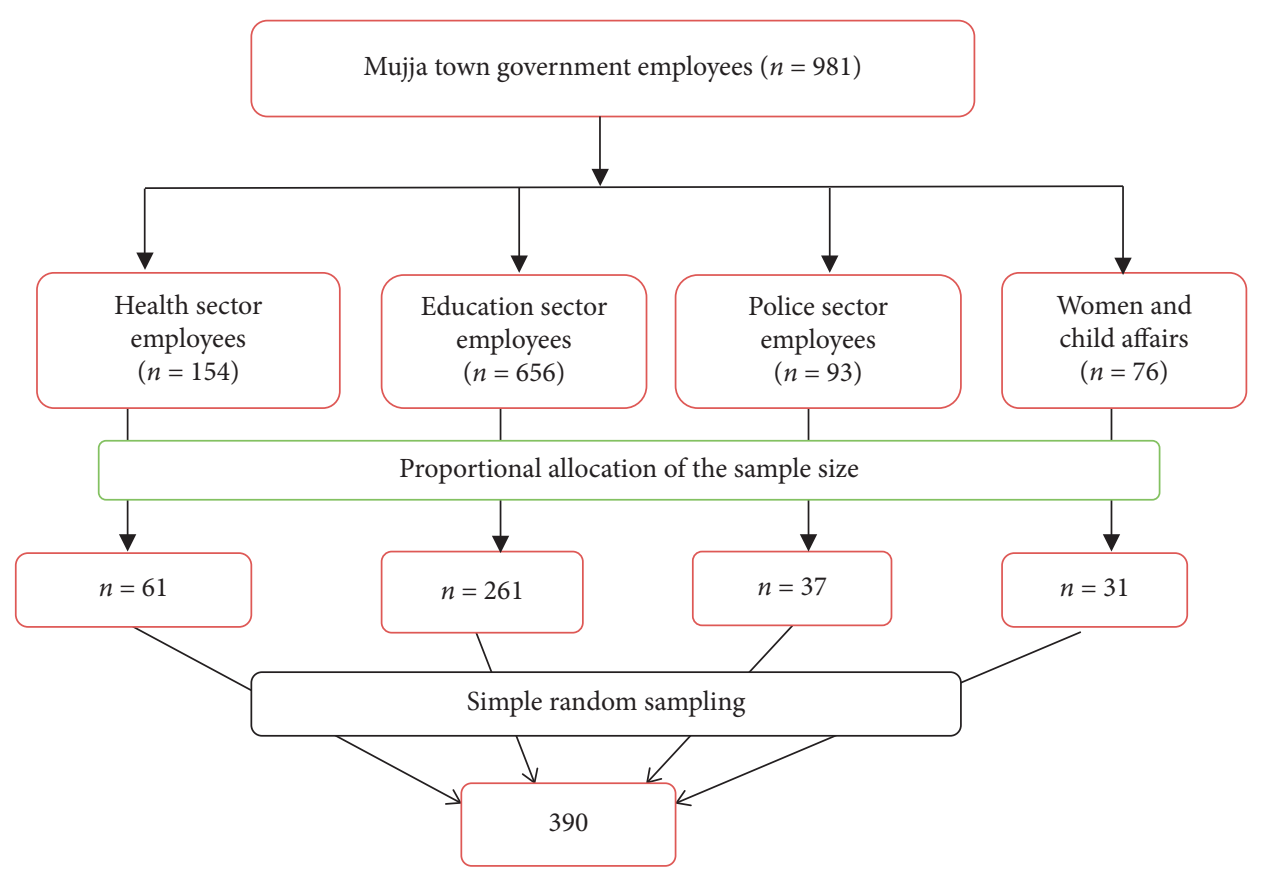

FIGURE 1: Schematic representations of the sampling procedure for willingness to pay to SHI and associated factors among government employees in Mujja town, northeast Ethiopia.

2.7. Data Management, Processing, and Analysis. Data were checked for incompleteness and inconsistency, edited, cleaned, coded, and entered into EPI info version 7 and exported to SPSS version 22.0 software for analysis. Descriptive statistics for categorical variables were presented using frequency and percentage.

Multi-collinearity among predictor variables was checked using standard error. Those variables with a standard error of two or more were considered having multi-collinearity, but no variable was found. The Omnibus test yielded a $p$ value $<0.0001$ with Hosmer and Lemeshow goodness of fit test $(p=0.969)$. Multivariable logistic regression was used to identify independent predictors of willingness to pay for SHI schemes by controlling confounding variables. Predictor variables with the $p$ value $<0.25$ at bivariable were included into the multivariable logistic regression model. The strength of association was measured through the adjusted odds ratio at a $95 \%$ confidence interval.

\subsection{Operational Definitions}

(i) Willingness to pay: volunteer to pay for the proposed first bid (3\% of monthly salary) of the premium. For those who did not ever hear about HI, information was given in detail about what SHI mean, its objective and payment-related and healthcare-related issues before asking them about their willingness to pay.

(ii) Full-time employees: employees who work for more than six months in a governmental institution for their full working time.

(iii) History of difficulty to cover medical bill(s): those who were suffering to cover the medical expense during previous illness times. (iv) Having other sources to cover medical bill: those whose medical expense is covered by other sources (the medical bill is not covered by their pocket money).

\section{Results}

3.1. Socio-Demographic Characteristics of Study Participants. A total of 375 study participants were included in this study with a response rate of $96.2 \%$. The majority, 337 (89.9\%), of the study participants were Amhara ethnic groups. Their mean $( \pm S D)$ age was $(30.59 \pm 7.05)$ years and two-thirds $(63.5 \%)$ of them were male. The median $( \pm \mathrm{IQR})$ monthly income of the respondents was $2493.824( \pm 1203.058)$ ETB (Table 1).

3.2. Health Status and Healthcare Utilization of the Individuals. Regarding preferences of treatment-seeking behavior during illness, 265 (70.7\%) of the study participants preferred governmental health facilities. Nearly two-thirds, 248 (66.1\%), of respondents paid for their medical bill out of pocket and 89 (23.7\%) employees' medical bill was covered by the government. Out of the total respondents, 238 (63.5\%) had a history of difficulty to cover their medical bills (Table 2).

3.3. Exposure and Perception towards SHI. Only 54 (14.4\%) of the employees have ever heard about the health insurance scheme. More than half, 215 (57.3\%), of the respondents had thought as government should pay for their SHI. Near to one-fourth $92(24.5 \%)$ of respondents believed that paying for their SHI is similar to monthly saving (Table 3 ). 
TABLE 1: Socio-demographic and economic characteristics of the government employees in Muja town, northeast Ethiopia, 2016 ( $n=375)$.

\begin{tabular}{|c|c|c|c|}
\hline Variable & Category & Frequency & Percent \\
\hline & $\leq 24$ & 54 & 14.4 \\
\hline & $25-29$ & 162 & 43.2 \\
\hline & $30-34$ & 66 & 17.6 \\
\hline Age & $35-39$ & 41 & 10.9 \\
\hline & $>40$ & 52 & 13.9 \\
\hline & Mean \pm SD & \multicolumn{2}{|c|}{$(30.59 \pm 7.05)$} \\
\hline \multirow{2}{*}{ Sex } & Male & 238 & 63.5 \\
\hline & Female & 137 & 36.5 \\
\hline \multirow{3}{*}{ Educational status of respondents } & Below diploma & 21 & 5.6 \\
\hline & Diploma & 173 & 46.1 \\
\hline & First degree and above & 181 & 48.3 \\
\hline \multirow{2}{*}{ Ethnicity } & Amhara & 337 & 89.9 \\
\hline & Others* & 38 & 10.1 \\
\hline \multirow{2}{*}{ Marital status } & Married & 203 & 54.1 \\
\hline & Not married & 172 & 45.9 \\
\hline \multirow{4}{*}{ Occupation } & Health & 58 & 15.4 \\
\hline & Police & 34 & 9.1 \\
\hline & Education & 255 & 68.0 \\
\hline & Women and child affairs & 28 & 7.5 \\
\hline \multirow{2}{*}{ Religion } & Orthodox & 338 & 90.1 \\
\hline & Others** & 37 & 9.9 \\
\hline \multirow{4}{*}{ Family size } & 1 & 101 & 26.9 \\
\hline & $2-3$ & 155 & 41.3 \\
\hline & $4-5$ & 91 & 24.3 \\
\hline & $\geq 6$ & 28 & 7.5 \\
\hline \multirow{5}{*}{ Monthly income (ETB) } & $<1400$ & 35 & 9.3 \\
\hline & $1401-2350$ & 178 & 47.5 \\
\hline & $2351-3550$ & 114 & 30.4 \\
\hline & $>3550$ & 48 & 12.8 \\
\hline & Median \pm IQR & \multicolumn{2}{|c|}{$2493.824( \pm 1203.058)$} \\
\hline
\end{tabular}

${ }^{*}$ Tigray, Oromo, and Afar. ${ }^{* *}$ Muslim, Protestant, and Catholic.

TABLE 2: Health status and healthcare utilization of the government employees in Muja town, northeast Ethiopia, $2016(n=375)$.

\begin{tabular}{|c|c|c|c|}
\hline Variable & Category & Frequency & Percent \\
\hline \multirow{3}{*}{ Preferences of treatment seeking during illness } & Governmental health facility & 265 & 70.7 \\
\hline & Private health facility & 78 & 20.8 \\
\hline & Traditional healers & 32 & 8.5 \\
\hline \multirow{2}{*}{ Chronic disease in the family } & Yes & 30 & 8 \\
\hline & No & 345 & 92 \\
\hline \multirow{3}{*}{ Payment management } & Government & 89 & 23.7 \\
\hline & Own money & 248 & 66.1 \\
\hline & Borrowed & 38 & 10.2 \\
\hline \multirow{2}{*}{ History of difficulty to cover medical bill(s) } & No & 238 & 63.5 \\
\hline & Yes & 137 & 36.5 \\
\hline \multirow{2}{*}{ Confidence to afford the care they need during illness } & Yes & 235 & 62.7 \\
\hline & No & 140 & 37.3 \\
\hline \multirow{2}{*}{ Having other source to cover medical bill } & Yes & 95 & 25.3 \\
\hline & No & 280 & 74.7 \\
\hline
\end{tabular}

3.4. Willingness to Pay for Social Health Insurance. In this study, $37.6 \%$ (95\% CI: 33.1\%, $42.61 \%$ ) of participants were willing to pay for the suggested insurance scheme (Table 4).
3.5. Factors Associated with Willingness to Payfor SHI. In the final multivariable logistic regression model, respondents who ever heard about health insurance schemes were seven times $(\mathrm{AOR}=7.205 ; 95 \% \mathrm{CI}: 1.385,37.475)$ more likely to be 
TABLE 3: Exposure and perception regarding SHI of the government employees in Muja town, northeast Ethiopia, $2016(n=375)$.

\begin{tabular}{|c|c|c|c|}
\hline Variable & Category & Frequency & Percent \\
\hline \multirow{2}{*}{ Ever heard about SHI } & Yes & 54 & 14.4 \\
\hline & No & 321 & 85.6 \\
\hline \multirow{4}{*}{ Who do you think should pay for insurance } & Employees & 19 & 5.1 \\
\hline & Employer & 72 & 19.1 \\
\hline & Government & 215 & 57.3 \\
\hline & Shared & 69 & 18.5 \\
\hline \multirow{2}{*}{ Believe that insurance is similar to monthly savings } & Yes & 92 & 24.5 \\
\hline & No & 283 & 75.5 \\
\hline \multirow{2}{*}{ Think insurance is a compensation if something bad happens } & Yes & 278 & 74.1 \\
\hline & No & 97 & 25.9 \\
\hline
\end{tabular}

TABLE 4: Willingness to pay for SHI among government employees in Muja town, northeast Ethiopia, 2016( $n=375)$.

\begin{tabular}{|c|c|c|c|}
\hline Variable & Category & Frequency & Percent \\
\hline \multirow{2}{*}{ WTP for SHI } & No & 234 & 62.4 \\
\hline & Yes & 141 & 37.6 \\
\hline \multirow{3}{*}{ Reason for not willing to pay for the social health insurance scheme $(n=234)$} & I am always in good health & 99 & 42.3 \\
\hline & SHI does not cover need & 126 & 53.8 \\
\hline & Fear of poor implementation & 9 & 3.9 \\
\hline
\end{tabular}

willing to pay as compared to those employees who never heard of social health insurance.

Respondents who had other sources to cover their medical bills were $92.6 \%(\mathrm{AOR}=0.074 ; 95 \% \mathrm{CI}: 0.009,0.612)$ less likely to be willing to pay for SHI than respondents having other sources.

Study participants who had a history of difficulty covering their medical bills were $94.6 \%(\mathrm{AOR}=0.054 ; 95 \% \mathrm{CI}$ : $0.011,0.257)$ less likely to pay for SHI than those who can pay for their medical bill (Table 5).

\section{Discussion}

This study showed that overall willingness to pay for SHI was $37.6 \%$ which was lower than a study done in Bahi Dar city (66.6\%) [22], Mekelle city (85.3\%) [23], Wolaita Sodo (74.4\%) [18], and Nigeria (89.7\%) [21]. This could be due to the difference in socio-demographic characteristics of study participants. But this study finding was slightly higher than other studies done in Ethiopia, Tigray region (35.5\%) [24], and Addis Ababa city $(28.7 \%, 17 \%)[25,26]$.

This study found that these respondents who ever heard about SHI, having a history of difficulty to cover their medical bills and having other sources to cover their medical bills, were the factors statistically significantly associated with willingness to pay for SHI.

In this study, respondents who ever heard about health insurance schemes were more likely to be willing to pay as compared to those employees who never heard. This is supported with a study done in southern Ethiopia, Wolaita Sodo town [18]. This could be due to that there was no health insurance scheme (SHI or $\mathrm{CBHI}$ ) in the town before and knowing about the benefits of health insurance is important to be willing to pay. This might be also due to having good awareness about health insurance and trust in a health insurance agency $[22,27,28]$.

Those who had other sources to cover their medical bill were less likely willing to pay for SHI. This maybe due to their medical cost being already covered and they consider it as extra cost $[19,20]$. This study might be also due to their higher income from other sources, which makes them able to cover their medical expense OOP money and by other sources $[23,26]$.

Furthermore, those who had no history of difficulty covering their medical bill were less likely willing to pay for SHI. This is consistent with a study revealed from the northern part of Ethiopia, Mekelle city [28], and southern Ethiopia, Wolaita Sodo town [18], Sierra Leone [27]. This might be due to that individuals who were unable to cover their medical bill may need risk-sharing nature of the insurance [29-31]. This might be due to the presence of abiding rule of referral system to get higher-level health services, exclusion of periodic medical checkup from SHI, poor perception of service quality, and presence of financial insecurity in government health institutions, the amount of premium contribution, and the perception that SHI will create a workload for health workers [23-25, 28].

4.1. Limitation of the Study. This study assessed the willingness to pay for SHI from participants who have insured and not insured sectors. Because of this, the respondents might have a higher ambition and expectation from the social health insurance before knowing the actual importance of SHI, which might have an effect on the magnitude of willingness to pay for SHI. Some variables were not measured such as wealth index and satisfaction on the quality of the healthcare services which might be predictive of 
TABLE 5: Factors associated with willingness to pay for SHI among government employees in Muja town, northeast Ethiopia, 2016 ( $n=375$ ).

\begin{tabular}{|c|c|c|c|c|}
\hline \multirow{2}{*}{ Variable/category } & \multicolumn{2}{|c|}{ WTP } & \multirow{2}{*}{ COR $(95 \%$ CI) } & \multirow{2}{*}{ AOR (95\%) } \\
\hline & Yes & No & & \\
\hline \multicolumn{5}{|c|}{ Ever heard about SHI } \\
\hline Yes & $36(66.7)$ & $18(33.3)$ & $4.114(2.231,7.587)$ & $7.205(1.385,37.475)^{*}$ \\
\hline No & $105(32.7)$ & $216(67.3)$ & 1 & 1 \\
\hline \multicolumn{5}{|c|}{ Having other source to cover medical bill } \\
\hline Yes & $12(12.6)$ & $83(87.4)$ & $0.169(0.088,0.324)$ & $0.074(0.009,0.612)^{*}$ \\
\hline No & $129(46.1)$ & $151(53.9)$ & 1 & 1 \\
\hline \multicolumn{5}{|c|}{ History of difficulty to cover medical bill } \\
\hline Yes & $102(74.5)$ & $35(25.5)$ & 1 & 1 \\
\hline No & $39(16.4)$ & $199(83.6)$ & $0.067(0.040,0.113)$ & $0.054(0.011,0.257)^{* *}$ \\
\hline
\end{tabular}

Those variable(s) statistically associated at binary logistic regressing with $p<0.25$ and entered to the final model were as follows: being heard about SHI, believing that insurance is similar to monthly saving, having other sources to cover a medical bill, history of difficulty to cover their medical bill, and having a chronic disease in the family. ${ }^{*} p$ value $<0.001$ and ${ }^{* *} p$ value $<0.005$.

willingness to pay for SHI. Another limitation of this study could be social desirability bias in which health professionals may tend to give favorable responses as they are the main stakeholders for sensitizing and implementing health-related policies. Hence, the conclusion of these findings should be interpreted considering these limitations.

\section{Conclusion}

In conclusion, this study revealed that willingness to pay for SHI was low. Being heard about health insurance, history of difficulty to cover their medical bills, and having other sources to cover their medical bill were associated factors of willingness to pay for SHI. Thus, it is recommended that media promotion for adequate awareness creation and the above factors should be considered with all employees at various levels for the successful implementation of the scheme. We recommend also other researchers to address other possible factors such as trust issues, quality services, wealth status, distance nearby health service, media coverage, and service satisfaction through various designs and methods.

\section{Abbreviations}

AOR: Adjusted odds ratio

CBHI: Community-based health insurance

CI: Confidence interval

ETB: Ethiopian birr

HI: Health insurance

OOP: Out of pocket

SHI: Social health insurance

UHC: Universal health coverage

WTP: Willingness to pay.

\section{Data Availability}

The data used in this study are available upon reasonable request to the corresponding author.

\section{Ethical Approval}

Ethical approval was obtained from Bahir Dar University Institutional Review Board of the College of Medicine and
Health Sciences. An official letter was obtained from the Amhara Regional Health Bureau and Woldia District Health and Administrative Offices.

\section{Consent}

The study objectives were explained to the study participants. Privacy and confidentiality of collected information were ensured at all levels and informed written consent was obtained.

\section{Conflicts of Interest}

The authors declare that there are no conflicts of interest.

\section{Authors' Contributions}

Feleku Mekonnen Degie conceived and designed the study, performed analysis, interpreted the data, and drafted the manuscript. The other co-authors involved in the design, analysis, and interpretation of the data and critically reviewed the manuscript and approved.

\section{Acknowledgments}

The authors would like to express their deepest gratitude to Bahir Dar University and Woldia Health Office for facilitating this study. Their appreciation also goes to data collectors and supervisors. Lastly, their heartfelt thanks go to the study participants for their willingness and positive cooperation.

\section{References}

[1] O. Doetinchem, G. Carrin, and D. Evans, "Thinking of introducing social health insurance? Ten questions," World Health Report, World Health Organization, Geneva, Switzerland, 2010.

[2] F. Morestin and V. Ridde, How Can the Poor be Better Integrated into Health Insurance Programs in Africa? An Overview of Possible Strategies, Policy Brief, University of Montreal, Montreal, Canada, 2009.

[3] A. Acharya, S. Vellakkal, S. Kalita et al., "Do social health insurance schemes in developing country settings improve health outcomes and reduce the impoverishing effect of 
healthcare payments for the poorest people," A Systematic Review, 2011.

[4] C. Averill and A. Marriott, Universal Health Coverage: Why Health Insurance Schemes Are Leaving the Poor behind, Oxfam International, Nairobi, Kenya, 2013.

[5] J. Bump, C. Cashin, K. Chalkidou et al., "Implementing propoor universal health coverage," The Lancet Global Health, vol. 4, no. 1, pp. e14-e16, 2016.

[6] A. Maeda, E. Araujo, C. Cashin, J. Harris, N. Ikegami, and M. R. Reich, Universal Health Coverage for Inclusive and Sustainable Development: A Synthesis of 11 Country Case Studies, The World Bank, Washington, DC, USA, 2014.

[7] World Health Organization, World Health Statistics 2010, World Health Organization, Geneva, Switzerland, 2010.

[8] G. Carrin and C. James, "Social health insurance: key factors affecting the transition towards universal coverage," International Social Security Review, vol. 58, no. 1, pp. 45-64, 2005.

[9] A. Dibaba, M. Hadis, S. Ababor, and Y. Assefa, Improving Health Care Financing in Ethiopia (SURE Policy Brief), Addis Ababa: Ethiopian Public Health Institute, Addis Ababa, Ethiopia, 2014.

[10] G. Purvis, A. Alebachew, and W. Feleke, Ethiopia Health Sector Financing Reform Midterm Project Evaluation, USAID, Washington, DC, USA, 2011.

[11] USAID, Health Care Financing Reform in Ethiopia: Improving Quality and Equity, USAID, Addis Ababa, Ethiopia, 2012.

[12] D. H. Mariam, "Exploring alternatives for financing health care in Ethiopia: an introductory review article," Ethiopian Journal of Health Development, vol. 15, no. 3, pp. 153-163, 2001.

[13] A. P. Fenny, R. Yates, and R. Thompson, Social Health Insurance Schemes in Africa Leave Out the Poor, Oxford University Press, Oxford, UK, 2018.

[14] A. Alebachew, Y. Yusuf, C. Mann, and P. Berman, Ethiopia's Progress in Health Financing and the Contribution of the 1998 Health Care and Financing Strategy in Ethiopia, Addis Ababa: Harvard TH Chan School of Public Health and Breakthrough International Consultancy, PLC, Boston, MA, USA, 2015.

[15] EPHIS, EVIPNet, An Evidence Brief for Policy, Executive Summary: Improving Health Care Financing in Ethiopia, 2014.

[16] T. Lavers, “Towards universal health coverage in Ethiopia's "developmental state"? The political drivers of health insurance," Social Science \& Medicine, vol. 228, pp. 60-67, 2019.

[17] A. Obse, M. Ryan, S. Heidenreich, C. Normand, and D. Hailemariam, "Eliciting preferences for social health insurance in Ethiopia: a discrete choice experiment," Health Policy and Planning, vol. 31, no. 10, pp. 1423-1432, 2016.

[18] T. Agago, M. Woldie, and S. Ololo, "Willingness to join and pay for the newly proposed social health insurance among teachers in Wolaita Sodo town, South Ethiopia," Ethiopian Journal of Health Sciences, vol. 24, no. 3, pp. 195-202, 2014.

[19] A. Kebede, M. Gebreslassie, and M. Yitayal, "Willingness to pay for community based health insurance among households in the rural community of Fogera District, North West Ethiopia," International Journal of Economics, Finance and Management Sciences, vol. 2, no. 4, pp. 263-269, 2014.

[20] A. Molla and N. Fentahun, "Predictors of willingness to participate in health insurance services among the community of Jimma town, Southwest Ethiopia," Health Services Insights, vol. 7, 2014

[21] I. B. Omotowo, U. E. Ezeoke, I. E. Obi et al., "Household perceptions, willingness to pay, benefit package preferences, health system readiness for National Health Insurance scheme in Southern Nigeria," Health, vol. 8, no. 14, pp. 1630-1644, 2016.

[22] S. Yeshiwas, M. Kiflie, A. A. Zeleke, and M. Kebede, "Civil servants' demand for social health insurance in Northwest Ethiopia," Archives of Public Health, vol. 76, no. 1, p. 48, 2018.

[23] M. T. Gidey, G. B. Gebretekle, M.-E. Hogan, and T. G. Fenta, "Willingness to pay for social health insurance and its determinants among public servants in Mekelle City, Northern Ethiopia: a mixed methods study," Cost Effectiveness and Resource Allocation, vol. 17, no. 1, p. 2, 2019.

[24] A. T. Gessesse, A. A. Berhe, M. G. Tilahun, and T. W. Teklemariam, Factors Associated with Willingness to Pay for Social Health Insurance Among Government Employees in Tigrai Region, Northern Ethiopia, Mzumbe University, Morogoro, Tanzania, 2016.

[25] Y. Lasebew, Y. Mamuye, and S. Abdelmenan, "Willingness to pay for the newly proposed social health insurance among health workers at st. Paul's hospital millennium medical College, Addis Ababa, Ethiopia," International Journal of Health Economics and Policy, vol. 2, no. 4, p. 159, 2017.

[26] A. Mekonne, B. Seifu, C. Hailu, and A. Atomsa, "Willingness to pay for social health insurance and associated factors among health care providers in Addis Ababa, Ethiopia," BioMed Research International, vol. 2020, Article ID 8412957, 7 pages, 2020.

[27] M. Jofre-Bonet and J. Kamara, "Willingness to pay for health insurance in the informal sector of Sierra Leone," PLoS One, vol. 13, no. 5, Article ID e0189915, 2018.

[28] A. Tewele, M. Yitayal, and A. Kebede, "Acceptance for social health insurance among health professionals in government hospitals, Mekelle city, North Ethiopia," Advances in Public Health, vol. 2020, Article ID 6458425, 9 pages, 2020.

[29] G. Carrin and C. James, "Key performance indicators for the implementation of social health insurance," Applied Health Economics and Health Policy, vol. 4, no. 1, pp. 15-22, 2005.

[30] J. De Weerdt and S. Dercon, "Risk-sharing networks and insurance against illness," Journal of Development Economics, vol. 81, no. 2, pp. 337-356, 2006.

[31] A. S. Preker and G. Carrin, Health Financing for Poor People: Resource Mobilization and Risk Sharing, The World Bank, Washington, DC, USA, 2004. 